\title{
LGR5 expression and clinicopathological features of the invasive front in the fat infiltration area of pancreatic cancer
}

\author{
Masato Kamakura', Takeshi Uehara², Mai Iwaya², Shiho Asaka², Shota Kobayashi², Tomoyuki Nakajima², \\ Yasuhiro Kinugawa², Tadanobu Nagaya', Takahiro Yoshizawa ${ }^{3}$, Akira Shimizu ${ }^{3}$, Hiroyoshi Ota ${ }^{2,4}$ and \\ Takeji Umemura ${ }^{1}$
}

\begin{abstract}
Background: Leucine-rich repeat-containing G-protein-coupled receptor 5 (LGR5) is a strong cancer stem cell marker in colorectal cancer; however, there are many unclear aspects of LGR5 expression in pancreatic cancer. It has been reported that the interaction between tumor cells and stroma at the fat infiltration site has a significant effect on pancreatic cancer prognosis. Therefore, we report a clinicopathological study of LGR5 expression at the fat invasion front in pancreatic cancer.

Methods: LGR5 expression was analyzed in 40 pancreatic ductal adenocarcinoma cases with RNAscope, which is a newly developed high-sensitivity in situ hybridization method. Epithelial-mesenchymal transition (EMT) was analyzed by the expression of E-cadherin and vimentin via immunohistochemistry.

Results: LGR5-positive dots were identified in all cases, especially with glandular formation. In the fat invasion front, a high histological grade showed significantly reduced LGR5 expression compared with a low histological grade $(p=$ 0.0126). LGR5 expression was significantly higher in the non-EMT phenotype group than in EMT phenotype group $(p=0.0003)$. Additionally, LGR5 expression was significantly lower in cases with high vascular invasion than in those with low vascular invasion $(p=0.0244)$.
\end{abstract}

Conclusions: These findings suggest that decreased LGR5 expression in the fat invasion front is associated with more aggressive biological behavior in pancreatic ductal adenocarcinoma, with higher tumor grade, EMT phenotype, and higher vascular invasion.

Keywords: Leucine-rich repeat-containing G-protein-coupled receptor 5 (LGR5), RNA in situ hybridization, Pancreatic ductal adenocarcinoma, cancer stem cell, Fat invasion

\section{Background}

Pancreatic cancer (PC) is the seventh leading cause of cancer-related deaths worldwide [1]. The prognosis of PC patients is extremely poor. Early detection is important to improve the prognosis of PC. For early detection

\footnotetext{
*Correspondence: tuehara@shinshu-u.ac.jp

${ }^{2}$ Department of Laboratory Medicine, Shinshu University School of Medicine, 3-1-1 Asahi, 390-8621 Matsumoto, Japan

Full list of author information is available at the end of the article
}

of $\mathrm{PC}$, it is useful to understand the risk factors of PC such as family history, hereditary pancreatitis, hereditary diseases such as hereditary breast and ovarian cancer syndrome, underlying diseases such as diabetes, and lifestyle such as smoking. If PC is suspected by abdominal ultrasonography, computed tomography, magnetic resonance imaging, endoscopic ultrasonography, and endoscopic retrograde cholangiopancreatography are used for examination, with the aim of early detection. However,

(c) The Author(s). 2022 Open Access This article is licensed under a Creative Commons Attribution 4.0 International License, which permits use, sharing, adaptation, distribution and reproduction in any medium or format, as long as you give appropriate credit to the original author(s) and the source, provide a link to the Creative Commons licence, and indicate if changes were made. The images or other third party material in this article are included in the article's Creative Commons licence, unless indicated otherwise in a credit line to the material. If material is not included in the article's Creative Commons licence and your intended use is not permitted by statutory regulation or exceeds the permitted use, you will need to obtain permission directly from the copyright holder. To view a copy of this licence, visit http://creativecommons.org/licenses/by/4.0/ The Creative Commons Public Domain Dedication waiver (http://creativecommons.org/publicdomain/zero/1.0/) applies to the data made available in this article, unless otherwise stated in a credit line to the data. 
few PCs are diagnosed early, and only approximately $2 \%$ of all PCs are diagnosed at Stage 0 or I [2]. Recently, preoperative or postoperative chemotherapy have been performed in addition to surgery for PC, even in patients with Stage II or higher disease [3]. However, the 5-year survival rate is $<10 \%$ [4].

Therefore, identifying factors that suggest prognosis in surgical materials is an important issue for PC. Most PCs are ductal adenocarcinomas (DAs) [5]. Analyzing the expression of various factors in DA or in the stroma surrounding DA may suggest important therapeutic targets. In this study, we focused on the expression of leucine-rich repeat-containing G-protein-coupled receptor 5 (LGR5) in DA. LGR5 was identified by lineage tracing to be a novel marker for adult stem cells in the small intestine, large intestine, and hair follicles [6] [7]. LGR5 is a seven transmembrane receptor [8] that is a target gene for Wnt/ $\beta$-catenin signaling [7]. LGR5 is recognized as a cancer stem cell (CSC) marker for colorectal cancer [9]. The possibility of LGR5 being associated with CSCs has also been pointed out in pancreatic cancer [10] [11]. Wnt/ $\beta$-catenin signaling is involved in various cellular functions including proliferation, migration, and drug resistance and is often dysregulated in cancer [12]. LGR5 is closely related to the control of Wnt/ $\beta$-catenin signaling [13] [14]. Wnt/ $\beta$-catenin signaling plays an important role in regulating the function of CSC [15]. LGR5 has been shown to be a stem cell marker in previous studies including for gastrointestinal mucosa and gastrointestinal tumors, in which LGR5 is the most promising stem cell marker. Subsequently, LGR5 expression has been revealed in many organs and tumors. We have previously investigated $L G R 5$ expression in pancreatic ducts and DA [11]. Recently, greater attention has been paid to the fact that the microenvironment of the tumor infiltration area is distinct and related to the infiltration of tumor cells [16]. In PC, it has been suggested that the altered tumor microenvironment in surrounding adipose tissue, such as fatty acid release at the tumor infiltration front, may promote metastasis [17]. Additionally, it has been reported that fat invasion by tumor cells is associated with a worse prognosis [18]. Therefore, we focused on the expression of LGR5 in the fat invasion front of DA and analyzed associations with clinicopathological features.

\section{Materials and methods \\ Patients}

We examined 52 cases of DA that were resected at Shinshu University between 2014 and 2019. Among them, eight cases with poor staining, one case with anaplastic carcinoma, and two cases without fat invasion were excluded. Stage II and III cases were also selected from the 52 total cases. Finally, 40 cases of DA with fat invasion were examined. We used the pancreatic tissue of a patient with extrahepatic cholangiocarcinoma for LGR5 expression analysis, as well as normal pancreas. We obtained clinicopathological data including gender, age, histological grade (HG), vascular invasion, tumor infiltrating lymphocytes (TILs), lymph node metastasis, stage, and prognosis. Stage and histology were reconfirmed based on the 8th edition of the Union International Cancer Control TNM staging system and the 4th edition of the World Health Organization classification. Histology was also reassessed by two pathologists (T.U. and M.I.). The scores of TILs were measured in the fat invasion and assessed using a four-tier score as follows: none, 0 ; mild, 1 ; moderate, 2 ; and marked, 3 [19]. TIL was measured in the region in which LGR5 expression was analyzed in one high-power field. Furthermore, TIL score was categorized as low-grade (score 0, 1 , and 2) or high-grade (3).

This study was performed in accordance with the current ethical guidelines of the Declaration of Helsinki and was conducted in accordance with the requirements of the Institutional Review Board of Shinshu University School of Medicine (approval No. 4088).

\section{Histopathology and immunohistochemistry}

We used surgically resected and formalin-fixed paraffinembedded DA tissues. Optimal lesions with fat invasion were selected from hematoxylin and eosin (HE)-stained specimens. A tissue microarray (TMA) was then created by the procedure described below. Tissue cores were punched out from each donor tumor block using thinwalled 3-mm stainless steel needles (Azumaya Medical Instruments Inc., Tokyo, Japan), and cores were arrayed into a recipient paraffin block. Serial Sect. $4 \mu \mathrm{m}$ in thickness were cut from these TMA blocks and stained with HE or immunostained with mouse monoclonal antibodies against E-cadherin (clone 36; dilution 1:2000; BD Biosciences, Franklin Lakes, NJ, USA) or vimentin (V9; dilution 1:50; Leica, Wetzlar, Germany). For antigen retrieval, sections were microwaved in $0.45 \%$ Tris $/ 5 \mathrm{mM}$ EDTA for $30 \mathrm{~min}$. Detection of the primary antibodies was performed using an Envision detection system (Agilent Technologies, Santa Clara, CA, USA) according to the manufacturers' recommendations. In accordance with a previous report [20], membranous E-cadherin expression was graded according to the proportion of positive cells and classified into four groups: $0,<10 \%$ of the cancer cells stained or with a complete absence of staining; $1,10-49 \%$ positive expression; $2,50-70 \%$ positive expression; and $3,>70 \%$ of cells with positive expression. Scores 0 and 1 were classified as E-cadherin negative, and scores 2 and 3 were classified as E-cadherin positive. For vimentin, clear positive staining in the cytoplasm of tumor cells was regarded as positive expression. We 
defined epithelial-mesenchymal transition (EMT) phenotypes into three groups according to the report by Aruga et al. [21]: non-EMT type, defined as E-cadherin positive and vimentin negative; incomplete EMT type, defined as E-cadherin negative and vimentin negative or E-cadherin positive and vimentin positive; and complete EMT type, defined as E-cadherin negative and vimentin positive. The incomplete EMT and complete EMT types were analyzed together as the EMT phenotype group and the non-EMT type was analyzed as the non-EMT phenotype group.

\section{LGR5 RNA in situ hybridization}

An RNAscope kit (Advanced Cell Diagnostics, Hayward, CA, USA) was used for LGR5 mRNA expression analysis of TMA. RNAscope is a recently developed in situ hybridization technique with high sensitivity and low background. RNAscope uses a specific double "Z-shaped" probe to hybridize to target RNA sequences (approximately 18-25 bases). The probe then binds to amplifier probes that bind the chromogenic label (DAB). Briefly, tissue sections were pretreated by heating, and protease was applied prior to hybridization with the LGR5-specific probe. The detailed procedure was described in a previous publication [22]. The standard positive control (MmPPIB, ACD-313,902) and negative control (DapB, $A C D-310,043)$ probes were used to ensure interpretable results. Brown punctate dots in the nucleus and/or cytoplasm indicated positive staining. LGR5 expression was quantified under a $20 \times$ or $40 x$ objective lens (Olympus BX51, Tokyo, Japan) according to the 5 -grade scoring system recommended by the manufacturer (Table 1) [23]. Furthermore, LGR5 mRNA expression was categorized into low expression (grades 0 and $1+$ ) and high expression (grades $2+, 3+$, and $4+$ ). We selected one case from each score category, performed LGR5 mRNA expression analysis in the whole section, and compared the

Table 1 Interpretation of RNAscope amplification score according to the manufacturer's guidelines. Staining scores 2, 3, and 4 were considered as high expression

\begin{tabular}{lc}
\hline Staining score & $\begin{array}{c}\text { LGR5 expression } \\
\text { score }\end{array}$ \\
\hline $\begin{array}{l}\text { 0, no staining or }<1 \text { dot every } 10 \text { cells, } \times 40 \\
\text { magnification } \\
1+, 1-3 \text { dots/cell, visible at } \times 20-40 \text { magnification }\end{array}$ & 11 \\
$2+, 4-9$ dots/cell, very few dot clusters, visible at & 12 \\
$\times 20-40$ magnification & \\
$\begin{array}{l}3+, 10-15 \text { dots/cell, }<10 \% \text { of positive cells with dot } \\
\text { clusters, visible at } \times 20-40 \text { magnification }\end{array}$ & 6 \\
$\begin{array}{l}\text { 4+, }>15 \text { dots/cell, }>10 \% \text { of positive cells with dot } \\
\text { clusters, visible at } \times 20 \text { magnification }\end{array}$ & 0 \\
\hline
\end{tabular}

scores in the fat invasion area. LGR5 expression in PC was measured in the region where LGR5 expression was strongest in the front of fat invasion. Additionally, the degree of cancer differentiation was also identified. Finally, we analyzed the relationship between LGR5 expression and clinicopathological data and prognosis in DA patients, with particular regard to the overall survival (OS) rate.

\section{Statistical analysis}

Fisher's exact test or Wilcoxon rank sum test were adopted to test for differences between patient subgroups. The survival rates of DA patients were calculated using the Kaplan-Meier method, and differences in those rates were compared by the Log-rank test. A $p$ value $<0.05$ was considered significant. All statistical analyses were performed using JMP Statistics software version 13 (JMP, Tokyo, Japan).

\section{Results \\ LGR5 expression and clinicopathological characteristics}

We first investigated LGR5 expression in normal pancreatic tissue. LGR5 staining was almost negative, but positive dots were detected in a very small number of intercalated ducts (Fig. 1).

LGR5-positive dots were identified in all cases (Fig. 2). Although the localization of LGR5-expressing cells was uncharacteristic, many were identified in differentiating ducts. Regarding PC with fat invasion, there were 18 cases with high $L G R 5$ expression and 22 cases with low LGR5 expression. Details are shown in Table 1. Relationships between clinicopathological variables and $L G R 5$ expression are shown in Table 2. LGR5 expression was significantly lower at the site fat invasion in the high $\mathrm{HG}$ group than in the low HG group $(p=0.0126)$. LGR5 scores were also significantly higher in the low HG group compared with the high HG group ( $p=0.0115)$ (Fig. 3). Furthermore, LGR5 expression was significantly lower in cases with high vascular invasion than in those with low vascular invasion $(p=0.0244)$. LGR5 expression was significantly higher in the non-EMT phenotype group than in the EMT phenotype group $(p=0.0006)$. The LGR5 expression score (score 1, 2, and 3) in fat invasion was consistent with TMA of the whole section.

The HGs were as follows: 30 low grade cases (Grade 2: 30 cases) and 10 high grade cases (Grade 3: 10 cases). All patients were treated with adjuvant chemotherapy and no patients had neoadjuvant chemotherapy. 


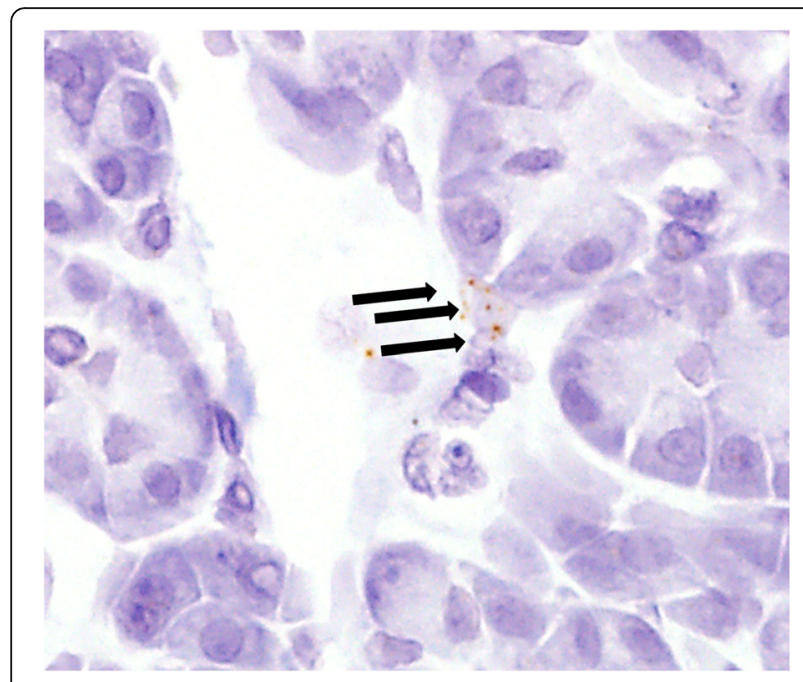

Fig. 1 LGR5 expression in normal pancreatic tissue. Positive dots were detected in intercalated ducts (arrows)

\section{Prognostic value of $L G R 5$ expression in pancreatic DA}

Next, we assessed the prognostic value of LGR5 expression in DA patients using Kaplan-Meier analysis and the log-rank test. The median survival of the entire DA patient group was $557.5 \mathrm{~d}$ (range: 293-1423 d). Logrank analysis showed no significant difference between OS in the high LGR5 expression group compared with in the low LGR5 expression group (median OS: $696.5 \mathrm{~d}$ [range, 261-1524 d] vs. $549.5 \mathrm{~d}$ [range, 306.5-1091.5], respectively; $p=0.6889$ ) (Fig. 4).

\section{Discussion}

Decreased expression of $L G R 5$ at the site of fat invasion in the high HG and EMT phenotype groups may suggest that LGR5 affects the prognosis of DA, indicating that it may be related to cancer cell EMT. EMT is a change that induces the acquisition of migration and invasion abilities by epithelial-derived cancer cells and plays an

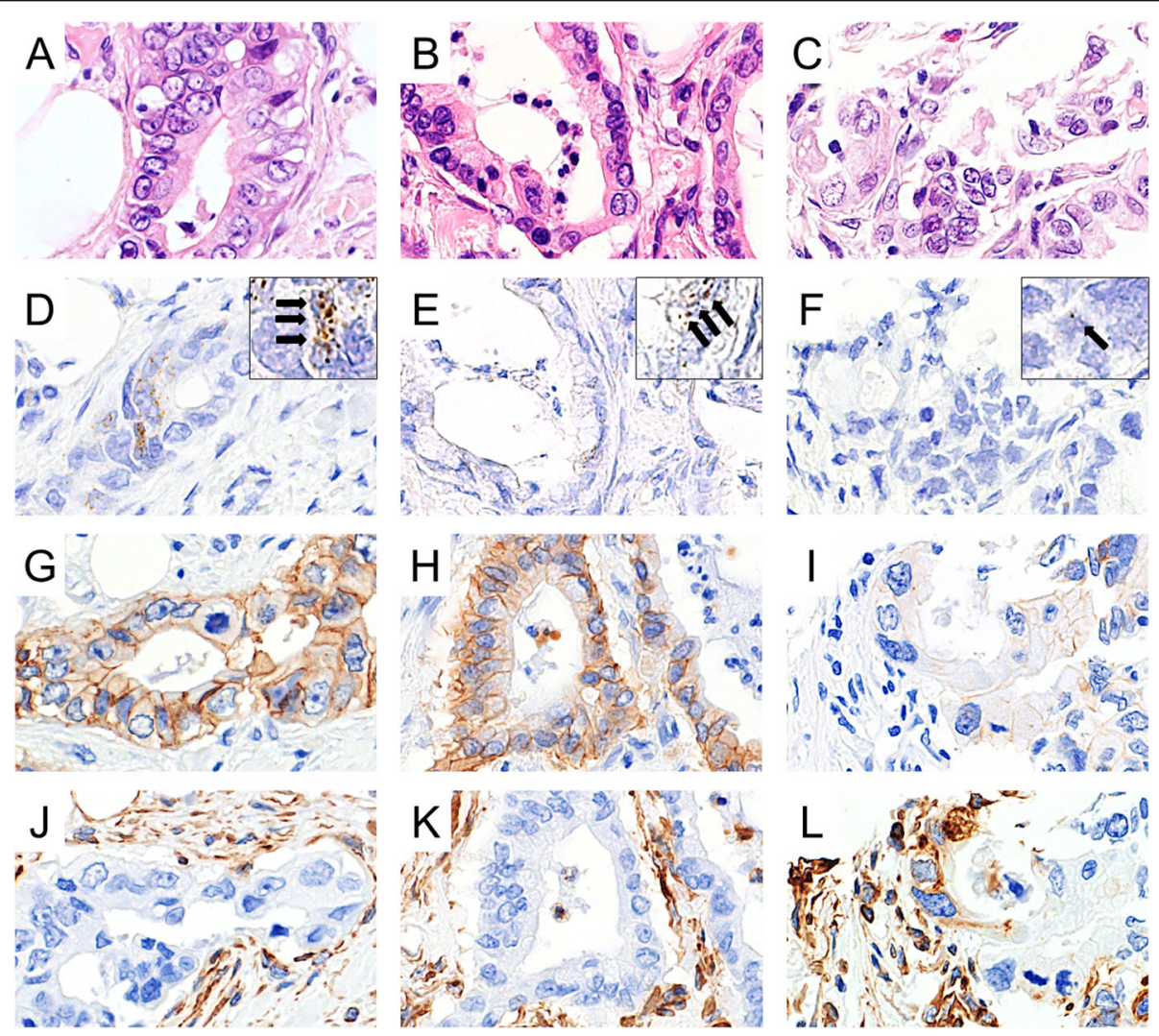

Fig. 2 LGR5 expression at the site of fat invasion. Representative hematoxylin and eosin (HE)-stained images of low histological grade (HG) (A and B) and high HG (C) tissues. In low HG tissues, LGR5 expression was relatively easy to identify (D and $\mathbf{E})$. Detailed images of $L G R 5$-positive dots (arrows) are shown in the insert image in D and $\mathrm{E}$. In high HG, low $L G R 5$ expression was identified (F). A detailed image of a $L G R 5$-positive dot (arrow) is shown in the insert image in F. In low HG tissues, E-cadherin expression was identified ( $\mathbf{G}$ and $\mathbf{H})$. In high HG, E-cadherin expression was not identified (I). In low HG tissues, vimentin expression was not identified ( $\mathbf{J}$ and $\mathbf{K}$ ). In high HG, vimentin expression was identified (L). (A, B, and C: HE staining, 40x magnification; D, E, and F: LGR5 RNAscope, 40x magnification [insert image 60x magnification]; G, H, and I: E-cadherin, 40X magnification; J, K, and L: vimentin, 40X magnification) 
Table 2 Associations between LGR5 expression and clinicopathological characteristics in pancreatic ductal adenocarcinoma

\begin{tabular}{|c|c|c|c|c|}
\hline \multirow[b]{2}{*}{ Factors } & \multirow[b]{2}{*}{$n$} & \multicolumn{2}{|c|}{ LGR5 expression } & \multirow[b]{2}{*}{$p$-value } \\
\hline & & High $(n=18)$ & Low $(n=22)$ & \\
\hline Age & & & & 0.7512 \\
\hline$\geq 69$ years & & 10 & 10 & \\
\hline$<69$ years & & 8 & 12 & \\
\hline Sex & & & & 1 \\
\hline Male & & 12 & 14 & \\
\hline Female & & 6 & 8 & \\
\hline Vascular invasion & & & & 0.0244 \\
\hline Present & & 6 & 16 & \\
\hline Absent & & 12 & 6 & \\
\hline TIL & & & & 0.4271 \\
\hline High & & 16 & 17 & \\
\hline Low & & 2 & 5 & \\
\hline Histological grade & & & & 0.0126 \\
\hline High & & 1 & 9 & \\
\hline Low & & 17 & 13 & \\
\hline EMT & & & & 0.0006 \\
\hline EMT phenotype & & 10 & 22 & \\
\hline Non-EMT phenotype & & 8 & 0 & \\
\hline TNM stage & & & & 0.4905 \\
\hline$\|$ & & 14 & 14 & \\
\hline III & & 4 & 8 & \\
\hline
\end{tabular}

TIL: tumor-infiltrating lymphocyte; TNM: tumor, node, metastasis staging system

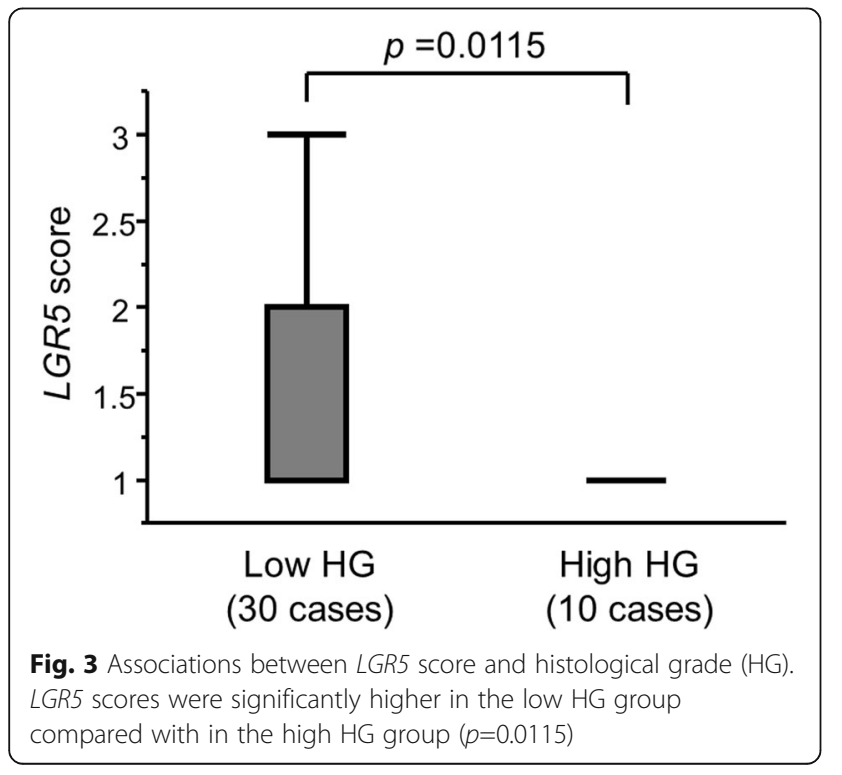

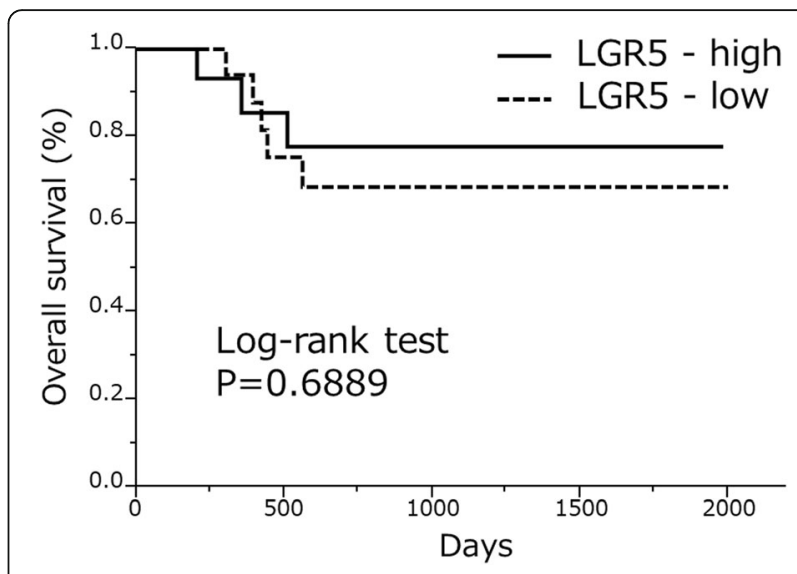

Fig. 4 Prognostic value of LGR5 by Kaplan-Meier analysis. There was no significant difference between overall survival (OS) in the high LGR5 expression group compared with that in the low LGR5 expression group (log-rank test $p=0.6889$ )

important role in the multi-step process that ultimately ends with distant metastases [24]. Therefore, increased HG that suggests EMT of cancer cells, which has a significant effect on prognosis. Increased HG may also be biologically associated with low $L G R 5$ expression. It has been reported that $L G R 5$ is strongly expressed in differentiated adenocarcinomas [11], as well as in other carcinomas such as colorectal cancer [25] [26]. Low LGR5 expression in high HG PC cases may have an important effect on prognosis, but further elucidation is warranted.

Low LGR5 expression in the site of fat invasion may lead to EMT. In an immunostaining study of the colorectum, vascular invasion was frequently identified with low LGR5 expression [27], which is consistent with our study. Although the above trends differ from some previous papers [28] [29], there are some molecular biological reports that reinforce our view. Low LGR5 expression may promote EMT, resulting in invasion and metastasis. Walker et al. reported that knocking down $L G R 5$ increased the activation of EMT genes and invasiveness of colorectal cancer cell lines [30]. Carmon et al. also reported that ablating $L G R 5$ resulted in decreased cell adhesion in colorectal cancer [31]. Jang et al. reported that LGR5 expression was associated with favorable prognosis and that LGR5 expression decreased migration in DLD1 cultured cells, which is one of the abilities gained by cells following EMT; however, they also found that LGR5 expression enhanced migration in other cultured colorectal cells [32]. They also reported that EMT-related transcription factors were not involved in LGR5-regulated gene expression. These functional difference in colorectal cancer cells may indicate the complexity of the pathway that influences $L G R 5$ expression during EMT. Additionally, the pathway that controls LGR5 expression during EMT may vary from organ to organ. Future elucidation is required. 
Several reports have shown that both EMT and cancer stem cell markers are expressed in PC [33] [34]. It has been reported that LGR5 and EMT-related transcription factors are co-expressed in intrahepatic cholangiocarcinoma [35], but re-verification of their LGR5 expression data by immunohistochemistry and re-verification RNA in situ is desired. Jang et al. also reported no correlation between LGR5 and the expression levels of other stem cell markers (CD133, CD44, CD24, and CD166) in colorectal cancer [32]. Therefore, LGR5 may have different biological characteristics from other CSC markers.

It has been reported that decreased LGR5 expression may be associated with abnormal methylation in colorectal cancer and bile duct cancer [32] [36]. In colorectal cancer, a relationship was highlighted between poor differentiation, lymph node metastasis, and low LGR5 expression due to hypermethylation [32]. Conversely, distant metastasis and prognosis are associated with high LGR5 expression due to hypomethylation [32], and the mechanism of methylation abnormalities has been identified. Methylation is closely related to microsatellite instability and may have effects on prognosis due to other factors. In this study, no significant correlation was found between LGR5 expression and the amount of inflammatory cell infiltration, which may affect methylation.

The invasion of fat by cancer cells is known to secrete various adipokines such as leptin, adiponectin, IL-6, CCL2, and CCL5 [37] [38]. In cultured PC cells, it has been reported that invasion and drug resistance are enhanced in a fat invasion model [17]. It has also been reported that cancer-associated adipocytes transferred from peripancreatic adipocytes in the pancreas enhance tumor cell migration, invasion, chemotherapy resistance, and EMT properties [39]. First reported in breast cancer cells, cancer-associated adipocytes are known to be involved in the activation of adipokine CCL2 and lead to the further activation of cancer stem cells [40]. Because LGR5 may have different properties than other cancer stem cell markers, there is an association between low LGR5 expression in fat invasion and cancer-associated adipocytes, especially CCL2, which may result in EMT.

In normal pancreas, LGR5 appears to be barely expressed or expressed in small amounts in some intercalated ducts. Our group previously reported similar results [11], indicating that LGR5 expression may be enhanced during pancreatic regeneration. However, its function in the normal pancreas has not yet been fully elucidated.

\section{Conclusions}

Although $L G R 5$ has been regarded as a promising cancer stem cell marker, its biological behavior may be different from other cancer stem cell markers; the exact function of $L G R 5$ remains unclear. The possibility of EMT occurring in cancer cells due to the involvement of $L G R 5$ and cancer-associated adipocytes needs to be reexamined by expression analysis in cultured cells. Our findings suggested that decreased LGR5 expression in the fat invasion front is associated with more aggressive biological behavior in pancreatic ductal adenocarcinoma, with higher tumor grade, EMT phenotype, and higher vascular invasion. Further study is warranted in the future.

\section{Abbreviations \\ PC: pancreatic cancer; DA: ductal adenocarcinoma; LGR5: leucine-rich repeat- containing G-protein-coupled receptor 5; HE: hematoxylin and eosin; OS: overall survival; HG: histological grade; EMT: epithelial-mesenchymal transition}

\section{Acknowledgements}

We are grateful to Yukihiro Kobayashi, Masanobu Momose, Yasuyo Shimojo, Naoko Ogiwara, Akiko Inamura, Chitoshi Arai, Marina Nuno, Kanade Wakabayashi, and Naoko Yamaoka at Shinshu University Hospital for their excellent technical assistance. We thank James P. Mahaffey, PhD, from Edanz (https://jp.edanz.com/ac) for editing a draft of this manuscript.

\section{Authors' contributions}

MK and TU participated in the design of the study, performed the pathological analysis, and drafted the manuscript. MI, SA, and SK helped with the pathological analysis. MK and TU performed statistical analysis. YK and TN conducted immunohistochemistry. TN, TY, AS, and TU examined the clinical data of the cases. $\mathrm{HO}$ and TU critically revised the draft manuscript for important intellectual content. The author(s) read and approved the final manuscript.

\section{Funding}

This study was partially supported by the Hokuto Foundation for Bioscience (grant awarded to T.U.). The funding body had no role in the study design, collection, analysis, or interpretation of data or manuscript writing.

\section{Availability of data and materials}

All data generated and analyzed during the current study are available from the corresponding author upon reasonable request.

\section{Declarations}

Ethics approval and consent to participate

This study was approved by the Ethics Committee of Shinshu University School of Medicine (Approval Code: 4088). The requirement of informed consent was waived, and an opt-out method was used because of the retrospective design of the study. The investigation was conducted in compliance with the Helsinki Declaration.

\section{Consent for publication}

Not applicable.

\section{Competing interests}

The authors declare that they have no competing interests.

\section{Author details}

'Department of Gastroenterology, Shinshu University School of Medicine, Matsumoto, Japan. ${ }^{2}$ Department of Laboratory Medicine, Shinshu University School of Medicine, 3-1-1 Asahi, 390-8621 Matsumoto, Japan. ${ }^{3}$ Department of Surgery, Shinshu University School of Medicine, Matsumoto, Japan.

${ }^{4}$ Department of Biomedical Laboratory Medicine, Shinshu University School of Medicine, Matsumoto, Japan. 
Received: 13 October 2021 Accepted: 20 January 2022

Published online: 05 February 2022

\section{References}

1. Bray F, Ferlay J, Soerjomataram I, Siegel RL, Torre LA. Jemal A Global cancer statistics 2018: GLOBOCAN estimates of incidence and mortality worldwide for 36 cancers in 185 countries. CA Cancer J Clin. 2018;68:394-424.

2. Kanno A, Masamune A, Hanada K, Maguchi H, Shimizu Y, Ueki T, et al. Multicenter study of early pancreatic cancer in Japan. Pancreatology. 2018; 18:61-7.

3. Klaiber U, Leonhardt CS, Strobel O, Tjaden C, Hackert T. Neoptolemos JP Neoadjuvant and adjuvant chemotherapy in pancreatic cancer. Langenbecks Arch Surg. 2018:403:917-32.

4. Yadav D, Lowenfels AB. The epidemiology of pancreatitis and pancreatic cancer. Gastroenterology. 2013;144:1252-61.

5. Sarantis P, Koustas E, Papadimitropoulou A, Papavassiliou AG, Karamouzis MV. Pancreatic ductal adenocarcinoma: Treatment hurdles, tumor microenvironment and immunotherapy. World J Gastrointest Oncol. 2020; 12:173-81.

6. Jaks V, Barker N, Kasper M, van Es JH, Snippert HJ, Clevers H, et al. Lgr5 marks cycling, yet long-lived, hair follicle stem cells. Nat Genet. 2008;40: 1291-9.

7. Barker N, van Es JH, Kuipers J, Kujala P, van den Born M, Cozijnsen M, et al. Identification of stem cells in small intestine and colon by marker gene Lgr5. Nature. 2007:449:1003-7.

8. Alizadeh-Navaei R, Rafiei A, Abedian-Kenari S, Asgarian-Omran H, Valadan R, Hedayatizadeh-Omran. A Comparison of leucine-rich repeat-containing $G$ protein-coupled receptor 5 expression in different cancer and normal cell lines. Biomed Rep. 2016:5:130-2.

9. Kemper K, Prasetyanti PR, De Lau W, Rodermond H, Clevers H. Medema JP Monoclonal antibodies against Lgr5 identify human colorectal cancer stem cells. Stem Cells. 2012;30:2378-86

10. Mizuno N, Yatabe Y, Hara K, Hijioka S, Imaoka H, Shimizu Y, et al. Cytoplasmic expression of LGR5 in pancreatic adenocarcinoma. Front Physiol. 2013;4:269.

11. Kuraishi Y, Uehara T, Kobayashi Y, Nakajima T, Watanabe T, Shimizu A, et al Correlation of clinicopathological features and leucine-rich repeatcontaining G-protein-coupled receptor 5 expression in pancreatic ductal adenocarcinoma. Pathol Res Pract. 2019:215:152623.

12. Shekarriz R, Montazer F, Alizadeh-Navaei R. Overexpression of cancer stem cell marker Lgr5 in colorectal cancer patients and association with clinicopathological findings. Caspian J Intern Med. 2019;10:412-6.

13. Glinka A, Dolde C, Kirsch N, Huang YL, Kazanskaya O, Ingelfinger D, et al. LGR4 and LGR5 are R-spondin receptors mediating Wnt/beta-catenin and Wnt/PCP signalling. EMBO Rep. 2011;12:1055-61.

14. Lin YU, Wu T, Yao Q, Zi S, Cui L, Yang M, et al. LGR5 promotes the proliferation of colorectal cancer cells via the Wnt/beta-catenin signaling pathway. Oncol Lett. 2015:9:2859-63.

15. Vermeulen L, De Sousa EMF, van der Heijden M, Cameron $K$, de Jong JH, Borovski $T$, et al. Wnt activity defines colon cancer stem cells and is regulated by the microenvironment. Nat Cell Biol. 2010;12:468-76.

16. Kibe S, Ohuchida K, Ando Y, Takesue S, Nakayama H, Abe T, et al. Cancerassociated acinar-to-ductal metaplasia within the invasive front of pancreatic cancer contributes to local invasion. Cancer Lett. 2019:444:70-81.

17. Okumura T, Ohuchida K, Sada M, Abe T, Endo S, Koikawa K, et al. Extrapancreatic invasion induces lipolytic and fibrotic changes in the adipose microenvironment, with released fatty acids enhancing the invasiveness of pancreatic cancer cells. Oncotarget. 2017:8:18280-95.

18. Jamieson NB, Foulis AK, Oien KA, Dickson EJ, Imrie CW, Carter R, et al. Peripancreatic fat invasion is an independent predictor of poor outcome following pancreaticoduodenectomy for pancreatic ductal adenocarcinoma. J Gastrointest Surg. 2011;15:512-24.

19. Ropponen KM, Eskelinen MJ, Lipponen PK, Alhava E, Kosma VM. Prognostic value of tumour-infiltrating lymphocytes (TILs) in colorectal cancer. J Pathol. 1997;182:318-24

20. Yamashita $N$, Tokunaga $E$, limori M, Inoue $Y$, Tanaka $K$, Kitao H, et al. Epithelial Paradox: Clinical Significance of Coexpression of E-cadherin and Vimentin With Regard to Invasion and Metastasis of Breast Cancer. Clin Breast Cancer. 2018;18:e1003-e9.

21. Aruga N, Kijima H, Masuda R, Onozawa H, Yoshizawa T, Tanaka M, et al. Epithelial-mesenchymal Transition (EMT) is Correlated with Patient's
Prognosis of Lung Squamous Cell Carcinoma. Tokai J Exp Clin Med. 2018;43: $5-13$

22. Ukpo OC, Flanagan JJ, Ma XJ, Luo Y, Thorstad WL, Lewis JS Jr. High-risk human papillomavirus E6/E7 mRNA detection by a novel in situ hybridization assay strongly correlates with p16 expression and patient outcomes in oropharyngeal squamous cell carcinoma. Am J Surg Pathol. 2011;35:1343-50.

23. Federmann B, Frauenfeld L, Pertsch H, Borgmann V, Steinhilber J, Bonzheim I, et al. Highly sensitive and specific in situ hybridization assay for quantification of SOX11 mRNA in mantle cell lymphoma reveals association of TP53 mutations with negative and low SOX11 expression. Haematologica. 2020;105:754-64

24. Thiery JP. Epithelial-mesenchymal transitions in tumour progression. Nat Rev Cancer. 2002;2:442-54.

25. Dame MK, Attili D, McClintock SD, Dedhia PH, Ouillette P, Hardt O, et al. Identification, isolation and characterization of human LGR5-positive colon adenoma cells. Development. 2018;145:dev153049.

26. Martin ML, Zeng Z, Adileh M, Jacobo A, Li C, Vakiani E, et al. Logarithmic expansion of LGR5(+) cells in human colorectal cancer. Cell Signal. 2018;42: 97-105.

27. Gzil A, Zarebska I, Jaworski D, Antosik P, Durslewicz J, Maciejewska J, et al. The prognostic value of leucine-rich repeat-containing G-protein (Lgr5) and its impact on clinicopathological features of colorectal cancer. J Cancer Res Clin Oncol. 2020;146:2547-57.

28. Sadek SA, DM AR, Fatima S. The role of tumor budding in colorecta adenocarcinoma: Possible involvement of the intestinal cancer stem cell marker Lgr5. Indian J Pathol Microbiol. 2020;63:32-7.

29. He S, Zhou H, Zhu X, Hu S, Fei M, Wan D, et al. Expression of Lgr5, a marker of intestinal stem cells, in colorectal cancer and its clinicopathological significance. Biomedicine \& pharmacotherapy = Biomedecine \& pharmacotherapie. 2014:68:507-13.

30. Walker F, Zhang HH, Odorizzi A, Burgess AW. LGR5 is a negative regulator of tumourigenicity, antagonizes Wnt signalling and regulates cell adhesion in colorectal cancer cell lines. PLoS One. 2011;6:e22733

31. Carmon KS, Gong X, Yi J, Wu L, Thomas A, Moore CM, et al. LGR5 receptor promotes cell-cell adhesion in stem cells and colon cancer cells via the IQGAP1-Rac1 pathway. J Biol Chem. 2017:292:14989-5001.

32. Jang BG, Kim HS, Chang WY, Bae JM, Kim WH, Kang GH. Expression Profile of LGR5 and Its Prognostic Significance in Colorectal Cancer Progression. Am J Pathol. 2018;188:2236-50.

33. Zhang Y, Liu Q, Liu J, Liao Q. Upregulated CD58 is associated with clinicopathological characteristics and poor prognosis of patients with pancreatic ductal adenocarcinoma. Cancer Cell Int. 2021;21:327.

34. Nomura A, Banerjee S, Chugh R, Dudeja V, Yamamoto M, Vickers SM, et al. CD133 initiates tumors, induces epithelial-mesenchymal transition and increases metastasis in pancreatic cancer. Oncotarget. 2015;6:8313-22.

35. Kawasaki K, Kuboki S, Furukawa K, Takayashiki T, Takano S, Ohtsuka M. LGR5 induces beta-catenin activation and augments tumour progression by activating STAT3 in human intrahepatic cholangiocarcinoma. Liver Int. 2021; 41:865-81.

36. Su S, Hong F, Liang Y, Zhou J, Liang Y, Chen K, et al. Lgr5 Methylation in Cancer Stem Cell Differentiation and Prognosis-Prediction in Colorectal Cancer. PLoS One. 2015:10:e0143513.

37. Cao Y. Adipocyte and lipid metabolism in cancer drug resistance. J Clin Invest. 2019:129:3006-17.

38. Zhao C, Wu M, Zeng N, Xiong M, Hu W, Lv W, et al. Cancer-associated adipocytes: emerging supporters in breast cancer. J Exp Clin Cancer Res. 2020;39:156

39. Takehara M, Sato Y, Kimura T, Noda K, Miyamoto H, Fujino $Y$, et al. Cancerassociated adipocytes promote pancreatic cancer progression through SAA1 expression. Cancer Sci. 2020:111:2883-94.

40. Wu Q, Li B, Li Z, Li J, Sun S, Sun S. Cancer-associated adipocytes: key players in breast cancer progression. J Hematol Oncol. 2019;12:95.

\section{Publisher's Note}

Springer Nature remains neutral with regard to jurisdictional claims in published maps and institutional affiliations. 